This is an electronic reprint of the original article. This reprint may differ from the original in pagination and typographic detail.

Author(s): Tero, Tiia-Riikka; Salorinne, Kirsi; Nissinen, Maija

Title: $\quad$ The Effect of Halogen Bonding on the Packing of Bromine Substituted Pyridine and Benzyl Functionalized Resorcinarene Tetrapodands in the Solid State

Year: $\quad 2012$

Version:

Please cite the original version:

Tero, T.-R., Salorinne, K., \& Nissinen, M. (2012). The Effect of Halogen Bonding on the Packing of Bromine Substituted Pyridine and Benzyl Functionalized Resorcinarene Tetrapodands in the Solid State. CrystEngComm, 14(21), 7360-7367. https://doi.org/10.1039/C2CE25972A

All material supplied via JYX is protected by copyright and other intellectual property rights, and duplication or sale of all or part of any of the repository collections is not permitted, except that material may be duplicated by you for your research use or educational purposes in electronic or print form. You must obtain permission for any other use. Electronic or print copies may not be offered, whether for sale or otherwise to anyone who is not an authorised user. 


\title{
The Effect of Halogen Bonding on the Packing of Bromine Substituted Pyridine and Benzyl Functionalized Resorcinarene Tetrapodands in the Solid State
}

\author{
Tiia-Riikka Tero, ${ }^{a}$ Kirsi Salorinne ${ }^{a}$ and Maija Nissinen ${ }^{a *}$ \\ ${ }_{5}$ Received (in $\left.X X X, X X X\right)$ Xth $X X X X X X X X X 20 X X$, Accepted Xth XXXXXXXXX 20XX \\ DOI: 10.1039/b000000x
}

The synthesis and characterization of new bromine substituted pyridine and benzyl functionalized tetramethoxy resorcinarene tetrapodands are described and their solid state structural properties and interactions were studied by single crystal X-ray crystallography. Three different crystal structures were

10 obtained for the pyridine derivative and one for the benzyl derivative, which revealed that the interactions of the bromine substituent have explicitly an effect on the crystal packing of the resorcinarene molecules. One of the structures obtained had very interesting halogen-halogen interaction with the same geometry as is generally found for compounds used in nonlinear optical studies.

\section{Introduction}

15 During the last two decades halogen bonding and its ability to impact intermolecular recognition processes have gained interest in the field of supramolecular chemistry. ${ }^{1}$ Since the halogen bonds are discovered to be highly directional ${ }^{2}$, they have widely been used in, for example, crystal engineering. ${ }^{3}$ In addition to 20 their role in structural chemistry, halogen bonds also affect the physical properties of crystalline materials, such as, second-order nonlinear optical (NLO) properties. ${ }^{4}$

Resorcinarenes are an important class of macrocyclic supramolecular hosts not only because of their concave aromatic ${ }_{25}$ cavity suitable for guest inclusion but also because of their easily modifiable framework that can be used to add specific functionality to their structure. ${ }^{5}$ Resorcinarenes and calixarenes are generally used in host-guest chemistry but possible material chemistry applications, such as their NLO properties, ${ }^{6}$ have also 30 received attention. Examples of such properties include selfassembled monolayers constituting of pyridine substituted calixarene-based NLO chromophoric pyramids on oxide surfaces $6^{\mathrm{a}-\mathrm{b}}$ and NLO materials formed by tetranitrocalix[4]arene derivatives. $6^{\mathrm{c}-\mathrm{f}}$

35 Halogen bonding has not yet been exploited in the design of calixarene or resorcinarene-based NLO applications but they have, however, been shown to have potential in host-guest chemistry, self-assembly and crystal packing of calixarenes and resorcinarenes. ${ }^{7,8}$ With calixarenes halogen bonding has been 40 utilized, for example, in ditopic ion transport systems where halogens of the receptor are used to bind an anion. ${ }^{7 a}$ It has also been observed that $\mathrm{C}-\mathrm{H} \cdots \mathrm{X}-\mathrm{R}(\mathrm{X}=$ halogen $)$ bonds play an important part in the complexation of basket like resorcinarenes with different halogen bearing guests. ${ }^{8}$ Dalgarno et al. ${ }^{9}$ have 45 reported that halogens of the lower rim halogenated pyrogallol[4]arenes affect dramatically the packing behavior of these molecules in the solid state compared to the unhalogenated pyrogallol[4]arenes.

During our on-going research of synthesizing new 50 supramolecular receptor molecules, we found that resorcinarenes bearing halogen substituents had interesting properties of their own. Herein, we report the synthesis and characterization of pyridine and benzyl functionalized tetramethoxy resorcinarene tetrapodands with a bromine substituent at the ortho- (pyridine ${ }_{55}$ derivative) or para-position (benzyl derivative). The solid state structural properties of the resorcinarene derivatives were studied by means of single crystal X-ray crystallography and a clear effect of bromines on the crystal packing in both the pyridine and the benzyl functionalized resorcinarene derivatives was observed. ${ }_{60}$ One of the crystal structures of the pyridine functionalized tetramethoxy resorcinarene revealed an intermolecular brominebromine interaction that has the same geometry as is observed with the smaller compounds applicable for new NLO materials. ${ }^{10}$

\section{Results and Discussion}

${ }_{65}$ Synthesis

The synthesis of tetramethoxy resorcinarene derivative $(3)$ with four bromine substituted pyridine side arms was obtained with a reasonable $43 \%$ yield. This nucleophilic substitution reaction was done by incorporating four 2-bromo-6-pyridylcarbinol units ${ }^{11}$ 70 (2) into the tetramethoxy resorcinarene platform $^{12}$ using anhydrous $\mathrm{K}_{2} \mathrm{CO}_{3}$ as the base and dibenzo-18-crown-6 as the phase-transfer-catalyst (PTC) in refluxing acetonitrile (Scheme 1).

The benzyl functionalized tetramethoxy resorcinarene (4) was 75 prepared by a similar nucleophilic substitution reaction of 4bromobenzyl bromide and the resorcinarene platform (1) with the exception that 18-crown- 6 was used as the PTC instead of 


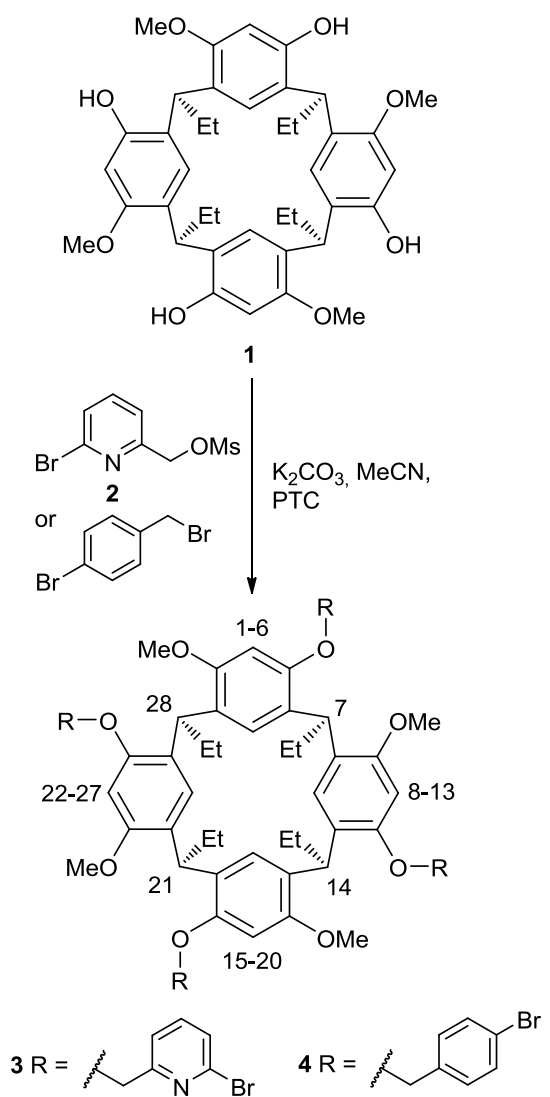

Scheme 1 Synthesis of the pyridine (3) and the benzyl (4) functionalized resorcinarene tetrapodands showing the crystallographic numbering.

dibenzo-18-crown-6 (Scheme 1). Stirring the mixture in dry ${ }_{5}$ acetone over night at $60{ }^{\circ} \mathrm{C}$ afforded the product 4 with $86 \%$ yield.

The compounds $\mathbf{3}$ and $\mathbf{4}$ were characterized by NMR spectroscopy $\left({ }^{1} \mathrm{H},{ }^{13} \mathrm{C}, \mathrm{HMBC}\right.$ and HMQC NMR), mass $\left(\mathrm{ESI}^{+}\right)$ spectrometry, X-ray crystallography and elemental analysis, 10 which all confirmed the success of the reactions.

\section{Structural properties}

Single crystals of the resorcinarene derivative $\mathbf{3}$ were grown from methanol-chloroform (structures I and III) and methanoldichloromethane solutions (structure II). The crystallization 15 solution of structure III contained also an excess amount of $\mathrm{Cu}\left(\mathrm{Cl}_{4} \mathrm{O}\right)_{2} \cdot 6 \quad \mathrm{H}_{2} \mathrm{O}$ because it was tested whether compound 3 would form solid state complexes with copper.t The crystal structure obtained in a triclinic space group $P-1$, however, did not contain copper but three chloroform molecules per a molecule of 20 3. Crystallization in the same solvent conditions without the copper salt, on the other hand, afforded structure $\mathbf{I}$ as a $1: 1$ chloroform solvate in a monoclinic space group $P 2_{1} / \mathrm{c}$. The crystallization from methanol-dichloromethane resulted in a dichloromethane solvate structure II in a triclinic space group $P-1$ 25 having two and a half dichloromethanes per one resorcinarene molecule $\mathbf{3}$.

The resorcinarene core in all of the structures $\mathbf{I}-$ III is in a slightly twisted boat conformation ${ }^{13}$ since there are no hydroxyl groups left on the upper rim that could form hydrogen bonds and, 30 thus, stabilize the resorcinarene core into a crown conformation

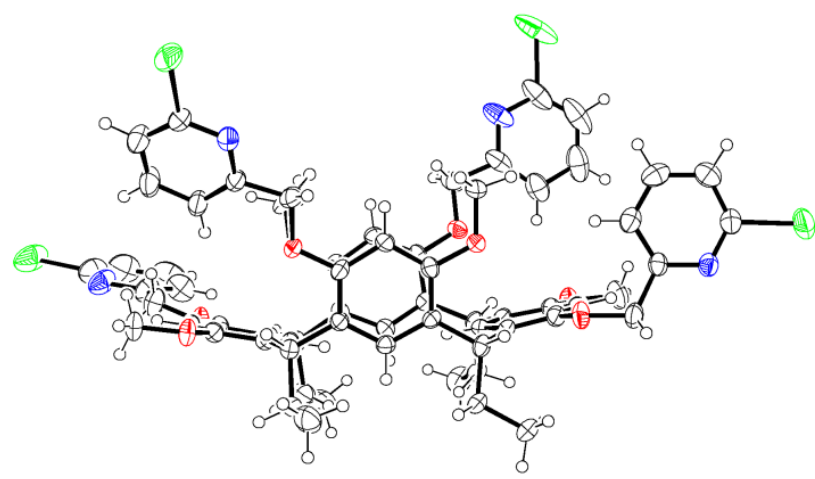

Fig. 1 A representative Ortep plot (50\% probability) of compound 3 showing the boat conformation of the resorcinarene platform (front view) shown here for structure $\mathbf{I}$.
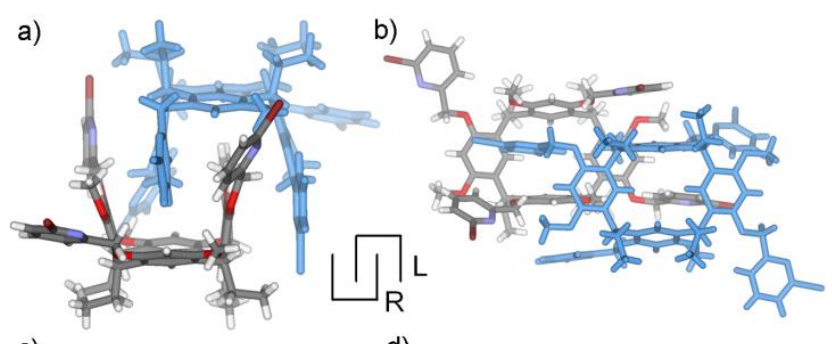

c)

d)

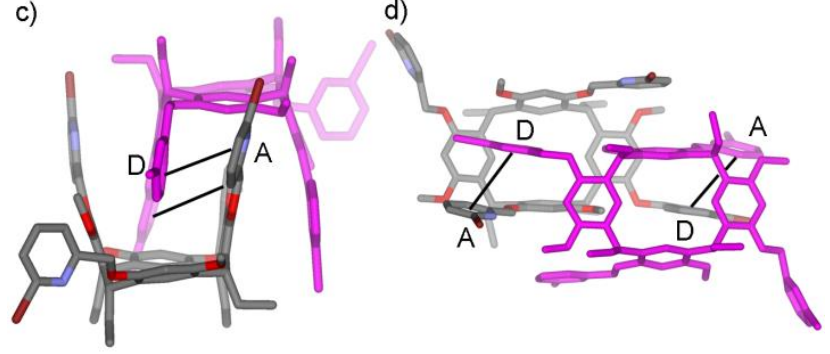

Fig. 2 The self-included dimeric pairs of compound $\mathbf{3}$ shown for structure I a) side and b) top views, and for structure II c) side and d) top views. The aromatic interactions between the pyridine arms A and D are highlighted as black lines. Letters $\mathrm{R}$ and $\mathrm{L}$ are used to implicate the right40 and the left-handed isomers, respectively, and the left-handed isomer is additionally presented with blue/red colour for clarity.

(Fig. 1). In the structures I-III the cavities of the resorcinarene cores are opened up as the opposite resorcinol rings are bent away from each other with the dihedral angles against the 45 methine plane of $97.2^{\circ}-106.8^{\circ}$ and $167.2^{\circ}-174.3^{\circ}$ for the upright and horizontal aromatic rings, respectively (Fig. 1). All of the structures form self-inclusion complexes, in which the cavities of the left- and right-handed isomers ${ }^{12}$ are facing one another and the pyridine arm D (see numbering in Fig. 3) fills the cavity of ${ }_{50}$ the opposite facing dimer pair and vice versa (Fig. 2).

The most important differences in the structures I-III are found in the details of the crystal packing of the resorcinarene molecules $\mathbf{3}$ and, especially, how the pyridine arms are positioned with respect to the resorcinarene skeleton. In each of the 55 structures three of the side arms (A, C and D) are pointing upwards and one is horizontally (B) oriented (Fig. 3). The pyridine arms $\mathrm{C}$ and $\mathrm{D}$ are furthermore positioned almost in the same way in all of these structures. In the structures II and III the pyridine ring $\mathrm{D}$, which is located inside the cavity of the opposite ${ }_{60}$ facing dimer pair, shows very weak intermolecular aromatic faceto-face type $\pi \cdots \pi$ interactions $(3.99-4.34 \AA)$ with the pyridine ring A of the dimer pair counterpart (Fig. 2c-d). In structure I 


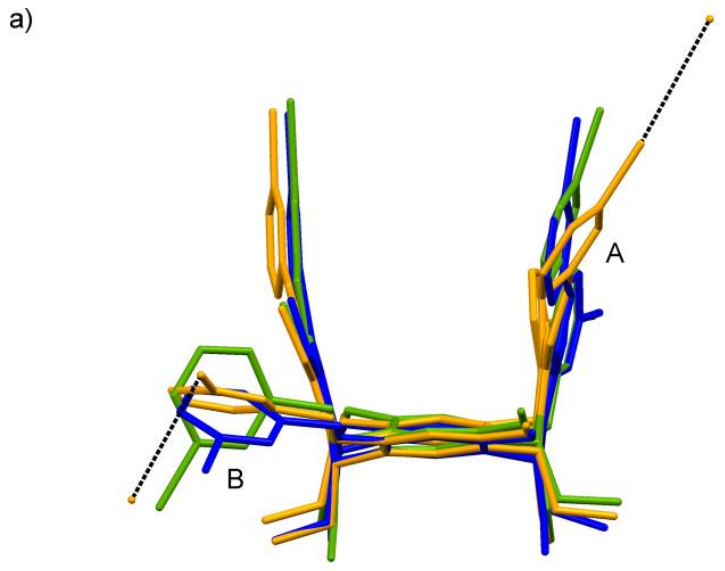

b)

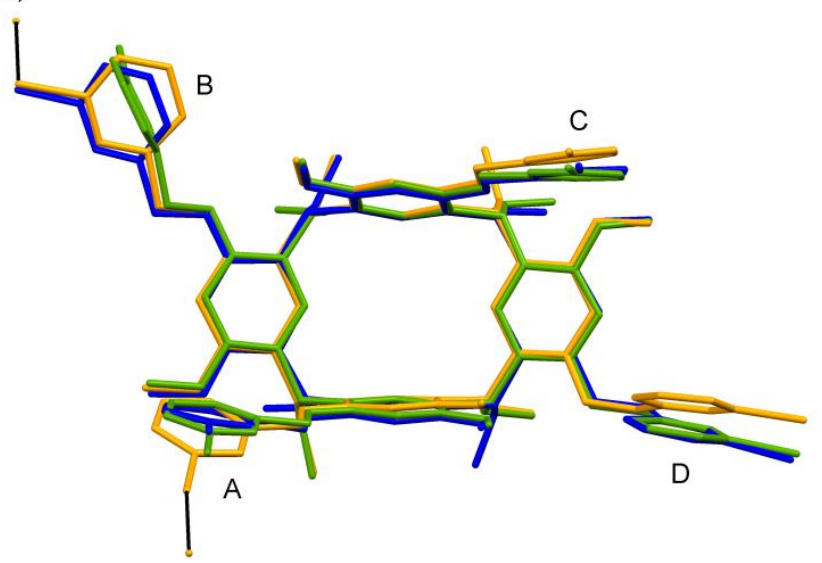

Fig. 3 a) Side and b) top views of the structures I (yellow), II (green) and III (blue) as a superposition drawing showing the difference in the positions of the pyridine-functionalized side arms (A-B). The black 5 dotted lines represent the directions of bromine-bromine interactions. Hydrogen atoms and solvent molecules have been omitted for clarity.

such aromatic interactions is not observed, which explains the small differences in the position of the pyridine ring $\mathrm{D}$ in comparison to the structures II and III. However, the major 10 differences are seen in the orientations in which the pyridine rings $\mathrm{A}$ and $\mathrm{B}$ are positioned. The pyridine ring $\mathrm{B}$ in structure $\mathbf{I}$ is aligned in the same direction as the horizontal aromatic rings of the resorcinarene core (Fig. 3a, yellow). In the structures II and III the same pyridine ring is turned more in the upright position, 15 i.e. $81.4^{\circ}$ and $37.5^{\circ}$ against the plane formed by atoms of the ring $\mathrm{B}$ in structure I (Fig. 3a, green and blue). Pyridine ring $\mathrm{A}$ in the structure $\mathbf{I}$ is tilted $18.0^{\circ}$ away from the resorcinarene cavity compared to the structures II and III, in which the pyridine rings A are in almost a parallel position with the adjacent upright 20 aromatic ring of the resorcinarene skeleton (Fig. 3b).

A closer inspection to the packing of the structures I-III revealed halogen-halogen interactions, which evidently influence the direction of the pyridine arms. The bromine of the pyridine ring $\mathbf{A}$ in structure $\mathbf{I}$ has a clear interaction with the bromine of 25 the pyridine ring B of the adjacent resorcinarene (Fig. 4, Table 1). In the structures II and III the corresponding rings have weak edge-to-face $(3.42 \AA)$ and face-to-face $(4.05 \AA)$ type $\pi \cdots \pi$ interactions, respectively, with the pyridine rings of the neighboring resorcinarenes but no obvious halogen-halogen 30 interactions are found (Table 1). The distance between the a)

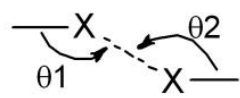<smiles>[Y]C1CC1[Y4]([R8])(Br)C(C)C</smiles>

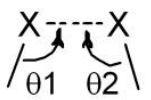

Type I (Close packing) $\theta 1=\theta 2=140-180^{\circ}$

Type II (L-geometry) $\theta 1=150-180^{\circ}$ $\theta 2=90-120^{\circ}$

-geometry $\theta 1=\theta 2$

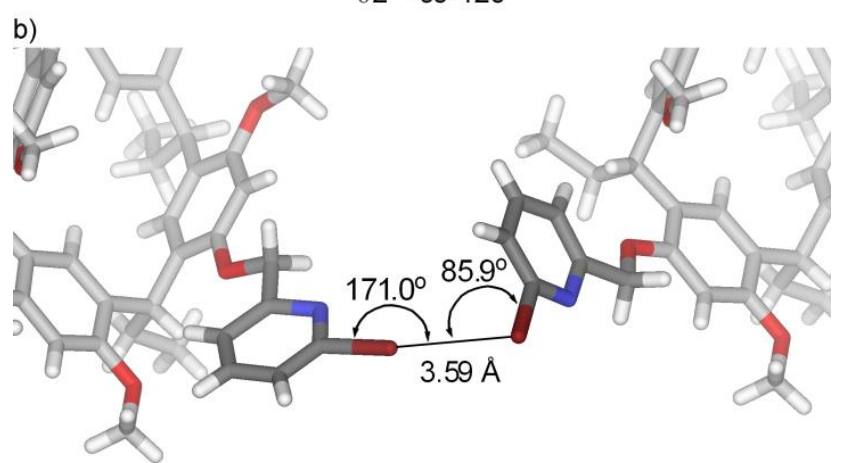

Fig. 4 a) The geometries of the halogen bonding ${ }^{10,14}$ and b) the angles and the distance of the intermolecular bromine-bromine interaction in structure $\mathbf{I}$ of the pyridine derivative $\mathbf{3}$. Only a cut-off of the structure is 35 shown highlighting the halogen bonding.

Table 1 Intermolecular halogen interactions of resorcinarenes $\mathbf{3}$ and $\mathbf{4}$ in the structures I-IV

\begin{tabular}{llllll}
\hline & \multirow{2}{*}{ Functionality } & \multirow{2}{*}{ Dimer type } & \multicolumn{3}{c}{ Halogen interactions } \\
& & & $\mathrm{Br} \cdots \mathrm{Br} / \mathrm{O} \mathrm{CH} \cdots \mathrm{Br}$ & Between the $\mathrm{DP}^{\mathrm{b}}$ \\
I & $\mathrm{Py}-\mathrm{Br}$ & $\mathrm{s}-\mathrm{i}^{\mathrm{a}}$ & yes & yes & no \\
II & $\mathrm{Py}-\mathrm{Br}$ & $\mathrm{s}-\mathrm{i}$ & no & no & yes $(\mathrm{CH} \cdots \mathrm{Br})$ \\
III & $\mathrm{Py}-\mathrm{Br}$ & $\mathrm{s}-\mathrm{i}$ & no & yes & no \\
IV & $\mathrm{Bn}-\mathrm{Br}$ & Parallel & yes & yes & no \\
${ }^{a}$ & Self-inclusion, ${ }^{\mathrm{b}}$ Dimer pair & & &
\end{tabular}

bromines in the bromine-bromine interaction in structure $\mathbf{I}$ is 3.59 ${ }_{40} \AA$, which is less than two times the van der Waals radius of bromine $(1.86 \AA)^{14}$ indicating a clear halogen-bonding interaction (Fig. 4).

Of the three different geometries identified for intermolecular halogen-halogen interactions ${ }^{10,14}$ - namely type I (close-packing), ${ }_{45}$ type II (L-geometry) and V-geometry - the observed angles $\left(171.0^{\circ}\right.$ and $\left.85.9^{\circ}\right)$ of the bromine-bromine interaction in structure I suite the type II geometry $\left(150-180^{\circ}\right.$ and $\left.90-120^{\circ}\right)$ the best (Fig. 4). In search of possible new crystalline NLO materials, it has been discovered, for example, that 2-halo-350 hydroxypyridine and 2-halo-3-aminopyridine rings (halo being either $\mathrm{Cl}, \mathrm{Br}$ or I) can have the type II (L-geometry) and $\mathrm{V}$ geometry, which are suitable for inducing the NLO properties. ${ }^{10}$ It has been observed that the type II geometry is not due to the closest packing, as is the case in type I geometry, but is stabilized 55 by specific attractive electrostatic forces affected by polarization. ${ }^{14,15}$ One of the angles $\left(171^{\circ}\right)$ in structure I corresponds well with type II, but the other angle $\left(85.9^{\circ}\right)$ is slightly smaller than the ones generally observed with smaller molecules of the type II geometry $\left(90-120^{\circ}\right)$. This might be due 60 to the large and bulky resorcinarene core that could affect the direction of the halogen bond in terms of structural restrain.

The bromine-bromine interaction directs the packing so that the neighboring same-handed isomers form a chain-like structure with each other as do their different-handed self-inclusion pairs ${ }_{65}$ (Fig. 5a-b). These chain structures line up in a stairway-like manner with a distance of $8.45 \AA$ between the "steps". $§$ The 


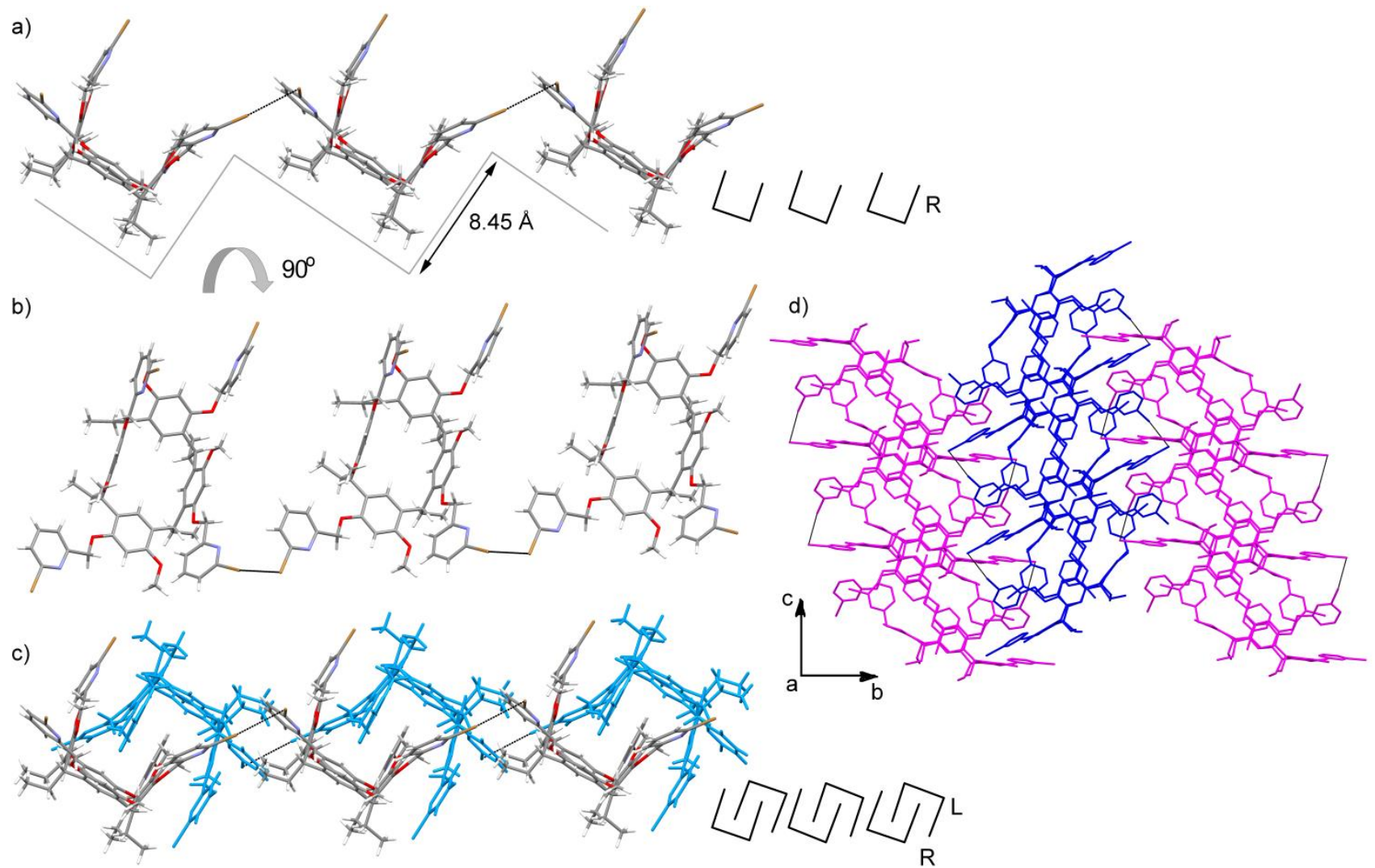

Fig. 5 The bromine-bromine interaction stabilized stairway-like chain formed by the right-handed isomers of the pyridine derivative $\mathbf{3}$ in structure $\mathbf{I}$ : a) side and b) top views, c) the self-inclusion of the stairway-like chains of the opposite inherent chirality and d) the crystal packing of these self-inclusion stairway-like chains viewed along the a-axis (hydrogen atoms and solvent molecules have been omitted for clarity). The bromine-bromine interactions are 5 shown as black lines.

adjacent stairway chains face the opposite direction while forming the self-inclusion pairs with their counterparts (Fig. 5c). In a closely related structure of a pyridine functionalized resorcinarene without a bromine substituent earlier published by ${ }_{10}$ McIldowie et al. ${ }^{16}$, similar self-inclusion structures of these resorcinarene derivatives form merely flat layers and the pyridine rings point remarkably to different directions than what was observed with the bromo-pyridine derivatives presented here. For example, unlike in the structures I-III, the structure of 15 McIldowie et al. ${ }^{16}$ has one of the pyridine arms attached to the upright aromatic ring of the resorcinarene skeleton pointing inside the cavity of the parent resorcinarene forming edge-to-face $\pi \cdots \pi$ interactions with the horizontal aromatic ring of the resorcinarene core, while the other three pyridine arms point 20 away from the cavity (see ESI). This furthermore indicates the directing effect of the bromine-bromine interactions.

Structure II created a stairway-like packing similar to the structure I although, in this case, there are no halogen-halogen interactions. In this structure, however, the edge-to-face $\mathrm{CH} \cdots \pi$ 25 interactions $(2.63 \AA)$ make the "steps" of the stairways smaller with a distance of $2.43 \AA$ between the steps (Fig. 6). $\S$ It seems that in this structure the actual halogen bonds, which are found between the molecules that form the dimer pairs, do not play that important part in the crystal packing. Also, the crystal packing in 30 structure III is a stairway-like, but unlike in the structures I and II, the steps are formed lengthwise between the self-inclusion complexes and are stabilized by weak face-to-face

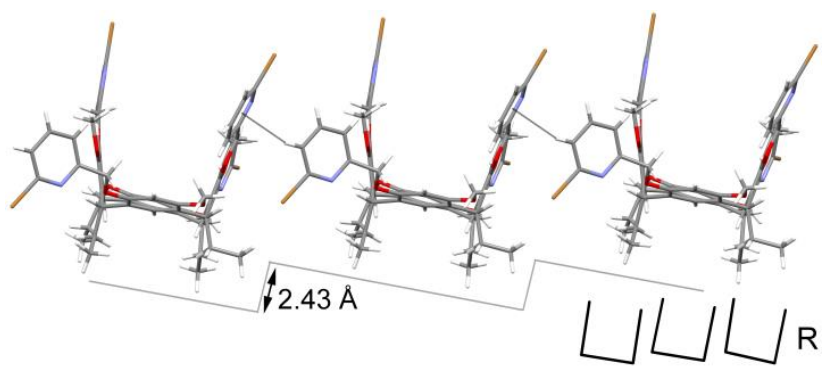

Fig. 6 The edge-to-face $\mathrm{CH} \cdots \pi$ interaction stabilized stairway-like chain 35 formed by the right-handed isomers of $\mathbf{3}$ in structure II. The aromatic interactions are shown as black lines.

$\pi \cdots \pi$ interactions (4.05 $\AA$ ) between the pyridine arms of the different-handed isomers (Fig. 7). In all of the structures the solvent molecules fill up the empty space between the 40 neighboring resorcinarene molecules. In the structure of McIldowie et al. ${ }^{16}$, the crystal packing is merely directed by $\mathrm{CH} \cdots \pi$ and $\pi \cdots \pi$ interactions. Interestingly, in the structures $\mathbf{I}$ and III, all halogen bonds observed are only between the neighboring resorcinarenes and not between the dimer pairs contrary to 45 structrure II where its only halogen bond $(\mathrm{CH} \cdots \mathrm{Br})$ was found between dimer pairs (Table 1).

The benzene derivative 4 (structure IV) formed suitable crystals (space group $P$-1) for single crystal structure determination from acetonitrile-chloroform solution at room 50 temperature. The asymmetric unit contains one acetonitrile per 


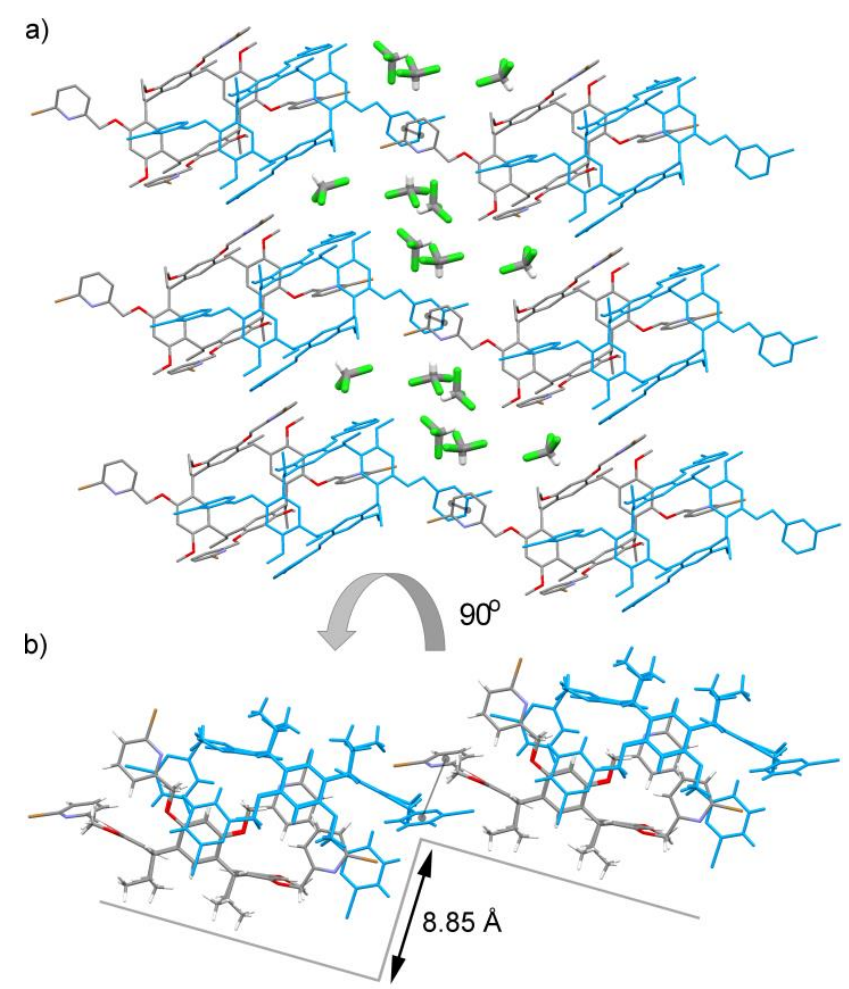

Fig. 7 a) A top view of the lengthwise stairway-like crystal packing of structure III and b) a front view of the "steps" showing the face-to-face $\pi \cdots \pi$ interaction between the two neighbouring different-handed 5 resorcinarene derivatives 3 . The left-handed isomers are coloured in blue, the hydrogen atoms of the resorcinarenes are omitted for clarity and the aromatic interactions are shown as black lines.

one resorcinarene molecule that is in a twisted boat conformation as expected (Fig. 8a). Unlike the pyridine functionalized 10 resorcinarene derivative $\mathbf{3}$, the benzene derivative $\mathbf{4}$ does not form self-inclusion structures; instead, the left- and right-handed isomers are parallel to one another with the cavities facing the opposite directions (Fig. 8b). The upright resorcinol rings in structure IV are inclined toward each other with an angle between 15 the upright aromatic rings of $8.9^{\circ}$ making the cavity more closed up and, thus, filling the empty space between the resorcinol rings. II $A s$ in the structures I-III, three of the side arms are somewhat in an upright position and the fourth one is horizontally oriented. No bromine-bromine interactions are observed but the 20 horizontal benzyl arm forms a halogen $\cdots$ O interaction $(3.22 \AA)$ between its bromine substituent and the methoxy oxygen of the neighbouring resorcinarene molecule. The structure resembles our earlier published structure of a benzyl functionalized resorcinarene tetrapodand without the bromine substituents, ${ }^{17}$ in 25 which the crystal packing is different due to the lack of the halogen bond. It again seems that the halogen bond has a significant effect on the packing by directing the position of the adjacent resorcinarenes with respect to each other via the weak intermolecular halogen interactions. Similar to the structures I 30 and III, the structure IV has halogen bonds only with the neighbouring resorcinarenes and not between the dimeric pairs (Table 1). a)

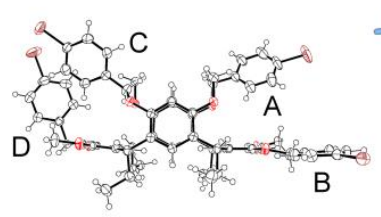

b)

c)

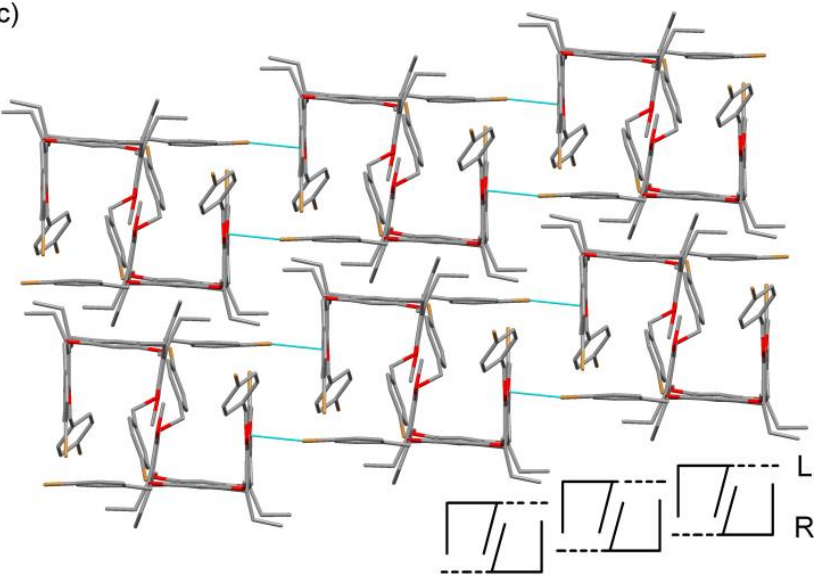

35 Fig. 8 a) Ortep plot (50\% probability) of structure IV (front view, benzyl arms A-D), b) a top view of two adjacent resorcinarene derivatives $\mathbf{4}$ of the opposite chirality and c) the crystal packing of the parallel dimer pairs (side view). Hydrogen atoms and solvent molecules have been omitted for clarity and halogen bonds between the bromine and oxygen atoms are 40 shown as blue lines.

\section{Conclusion}

In conclusion, the synthesis and structural properties of two new halogen functionalized resorcinarene derivatives - one bearing four bromine substituted pyridine rings and the other bearing four 45 bromine substituted benzyl rings - are reported. The crystal structures of these compounds showed that the bromine substituents have an important role in the crystal packing. One of the three structures of the pyridine functionalized resorcinarene had an intermolecular bromine-bromine interaction between the 50 adjacent resorcinarene molecules with a similar halogen-halogen interaction geometry that is often observed with potential NLO materials. However, even though halogen-halogen interactions was not observed in the other two structures of the pyridine derivatives, their crystal packing was nonetheless very different 55 compared to the structure of the pyridine functionalized resorcinarene without any halogen substituents that was earlier published by McIldowie et al. ${ }^{16}$

In the structure of the benzene functionalized resorcinarene there was a clear indication of intermolecular halogen interactions 60 between the neighbouring resorcinarenes that directed the crystal packing. When comparing this to a structure of a benzyl functionalized resorcinarene without the halogen substituents, ${ }^{17}$ the effect of the halogen bond to the observed differences in the crystal packing was clear: it directs the position of the adjacent 65 resorcinarenes. Encouraged by the promising structural results, our future studies will focus on exploring the material aspects of these halogenated resorcinarene derivatives in more detail. 
Table 2 Summary of the crystal data and structure refinement details

\begin{tabular}{|c|c|c|c|c|}
\hline & $\mathbf{I}$ & II & III & IV \\
\hline Composition & $\mathrm{C}_{64} \mathrm{H}_{64} \mathrm{O}_{8} \mathrm{Br}_{4} \mathrm{~N}_{4} \cdot \mathrm{CHCl}_{3}$ & $\mathrm{C}_{64} \mathrm{H}_{64} \mathrm{Br}_{4} \mathrm{~N}_{4} \mathrm{O}_{8} \cdot 2.5 \mathrm{CH}_{2} \mathrm{Cl}_{2}$ & $\mathrm{C}_{64} \mathrm{H}_{64} \mathrm{O}_{8} \mathrm{Br}_{4} \mathrm{~N}_{4} \cdot 3 \mathrm{CHCl}_{3}$ & $\mathrm{C}_{68} \mathrm{H}_{68} \mathrm{O}_{8} \mathrm{Br}_{4} \cdot \mathrm{CH}_{3} \mathrm{CN}$ \\
\hline Formula weight & 1456.20 & 1549.15 & 1694.94 & 1373.92 \\
\hline Crystal system & Monoclinic & Monoclinic & Triclinic & Triclinic \\
\hline Space group & $P 2_{1} / \mathrm{c}$ & $P 2_{1} / \mathrm{n}$ & $P-1$ & $P-1$ \\
\hline a/Å & $14.9256(3)$ & $13.645(1)$ & $14.3290(3)$ & $13.0274(4)$ \\
\hline$b / \AA$ & $29.5166(7)$ & $35.308(3)$ & $16.2799(4)$ & $15.5167(5)$ \\
\hline$c / \AA$ & $15.9571(4)$ & $13.891(1)$ & $17.1585(5)$ & $17.6396(7)$ \\
\hline$\alpha /^{\circ}$ & 90 & 90 & $73.013(1)$ & $77.702(2)$ \\
\hline$\beta /{ }^{\circ}$ & $116.337(2)$ & $96.576(4)$ & $68.370(1)$ & $75.161(2)$ \\
\hline$\gamma /{ }^{\circ}$ & 90 & 90 & 87.773(1) & $68.214(2)$ \\
\hline$V / \AA^{3}$ & $6300.2(3)$ & $6648.3(9)$ & $3547.8(2)$ & $3172.9(2)$ \\
\hline $\mathrm{Z}$ & 4 & 4 & 2 & 2 \\
\hline$D_{\mathrm{c}} / \mathrm{Mg} \mathrm{m}^{-3}$ & 1.535 & 1.548 & 1.587 & 1.438 \\
\hline$\mu(\mathrm{Cu} \mathrm{K} \alpha) / \mathrm{mm}^{-1}$ & 4.757 & 5.267 & 6.345 & 3.539 \\
\hline$F(000)$ & 2952 & 3140 & 1708 & 1404 \\
\hline Crystal size/mm & $0.15 \times 0.05 \times 0.05$ & $0.16 \times 0.10 \times 0.03$ & $0.35 \times 0.20 \times 0.15$ & $0.20 \times 0.15 \times 0.05$ \\
\hline Theta range for data collection $/^{\circ}$ & 2.99 to 67.03 & 3.44 to 66.13 & 2.85 to 67.14 & 2.61 to 66.88 \\
\hline Reflections collected & 20997 & 18043 & 17643 & 16002 \\
\hline Independent reflections & $10896[\mathrm{R}(\mathrm{int})=0.0643]$ & $10449[\mathrm{R}(\mathrm{int})=0.0863]$ & $12280[\mathrm{R}(\mathrm{int})=0.0626]$ & $11003[\mathrm{R}(\mathrm{int})=0.0405]$ \\
\hline Restrains/parameters & 18,801 & 19,822 & 0,837 & 0,757 \\
\hline GOF on $F^{2}$ & 1.024 & 1.048 & 1.030 & 1.041 \\
\hline$R 1$ and $R 2[I>2 \sigma(I)]$ & $0.0749,0.1699$ & $0.0898,0.2198$ & $0.0533,0.1383$ & $0.0462,0.1088$ \\
\hline$R 1$ and $R 2$ (all data) & $0.1263,0.1998$ & $0.1775,0.2870$ & $0.0585,0.1428$ & $0.0602,0.1186$ \\
\hline Largest difference peak and hole/e $\AA^{-3}$ & $2.815,-2.262$ & $0.741,-0.742$ & $2.070,-1.762$ & $1.198,-1.009$ \\
\hline
\end{tabular}

\section{Experimental}

\section{General}

${ }_{5}^{1} \mathrm{H},{ }^{13} \mathrm{C}$, HMQC and HMBC NMR spectra were recorded on a Bruker Avance DRX (500 MHz for ${ }^{1} \mathrm{H}$ and $126 \mathrm{MHz}$ for ${ }^{13} \mathrm{C}$ ) spectrometer. ESI mass spectrum was measured with Micromass LCT ESI-TOF instrument. Melting points were obtained with Stuart Scientific SMP3 melting point apparatus and are 10 uncorrected. Tetramethoxy resorcinarene ${ }^{12}$ and the mesylated 2bromo-6-pyridylcarbinol ${ }^{11}$ were prepared according to the literature procedures. All other reagents used were commercial and used as received. Acetonitrile was distilled over $\mathrm{CaCl}_{2}$ and stored over Linde type $3 \AA$ molecular sieves prior use. $\mathrm{K}_{2} \mathrm{CO}_{3}$ 15 was dried in the oven at $120^{\circ} \mathrm{C}$ and stored in a desiccator.

\section{Synthesis of compound 3}

A mixture of tetramethoxy resorcinarene $\mathrm{e}^{12}(0.20 \mathrm{~g}, 0.31 \mathrm{mmol})$, $\mathrm{K}_{2} \mathrm{CO}_{3}(0.36 \mathrm{~g}, 2.60 \mathrm{mmol})$ and dibenzo-18-crown-6 (0.06 g, $0.17 \mathrm{mmol})$ was suspended in dry acetonitrile $(25 \mathrm{ml})$ under 20 nitrogen and refluxed for $45 \mathrm{~min}$ before the dropwise addition of mesylated 2-bromo-6-pyridylcarbinol ${ }^{11}(0.35 \mathrm{~g}, 1.31 \mathrm{mmol})$ in acetonitrile $(5 \mathrm{ml})$. The resulting suspension was refluxed for 27 $\mathrm{h}$, during which the colour changed from white to yellow. The warm reaction mixture was filtered by suction through a pad of ${ }_{25}$ Hyflo Super®. Chloroform was filtered through the same pad of Hyflo Super® in case that the product had crystallized during filtration. The solvents were evaporated under vacuum. The residue was dissolved in chloroform and washed with water and with brine. The organic layer was dried with $\mathrm{MgSO}_{4}$ and the 30 solvents evaporated to dryness under vacuum. Purification by Flash chromatography on silica gel using ethyl acetate-hexane (2:3) as the eluent afforded $0.18 \mathrm{~g}(43 \%)$ of solid white powder. ${ }^{1} \mathrm{H}$ NMR: $\left(\mathrm{CDCl}_{3}, 500 \mathrm{MHz}\right) \delta 0.97\left(12 \mathrm{H}, \mathrm{t}, \mathrm{J}=7.23 \mathrm{~Hz}, \mathrm{CH}_{3}\right)$, $1.93\left(8 \mathrm{H}\right.$, quin, $\left.\mathrm{J}=7.26 \mathrm{~Hz}, \mathrm{CH}_{2}\right), 3.47(12 \mathrm{H}, \mathrm{s}, \mathrm{OMe}), 4.50(4 \mathrm{H}$ $\left.{ }_{35} \mathrm{t}, \mathrm{J}=7.45 \mathrm{~Hz}, \mathrm{CH}\right), 4.90(8 \mathrm{H}, \mathrm{AB}$ quartet, $\mathrm{J}=13.90$ and 95.07 $\left.\mathrm{Hz}, \mathrm{CH}_{2}\right), 6.33(4 \mathrm{Hs}, \mathrm{ArH}), 6.71(4 \mathrm{H}, \mathrm{s}, \mathrm{ArH}), 7.31(4 \mathrm{H}, \mathrm{d}$, $\mathrm{J}=7.60 \mathrm{~Hz}, \mathrm{PyH}), 7.36(4 \mathrm{H}, \mathrm{d}, \mathrm{J}=7.85 \mathrm{~Hz}, \mathrm{PyH}), 7.44(4 \mathrm{H}, \mathrm{t}$, $\mathrm{J}=7.73 \mathrm{~Hz}, \mathrm{PyH}) \mathrm{ppm} .{ }^{13} \mathrm{C} \mathrm{NMR}:\left(\mathrm{CDCl}_{3}, 126 \mathrm{MHz}\right) \delta 13.0$, 27.6, 37.6, 55.7, 70.6, 97.2, 119.9, 125.9, 126.4, 126.5, 126.7, 40 139.1, 141.1, 154.6, 155.9, $159.8 \mathrm{ppm}$. MS (ESI-TOF): $\mathrm{m} / \mathrm{z}$ $1359.17[\mathrm{M}+\mathrm{Na}]^{+}$. Anal. Calcd. for $\mathrm{C}_{64} \mathrm{H}_{64} \mathrm{O}_{8} \mathrm{~N}_{4} \mathrm{Br}_{4}$ : C, 57.50; H, 4.83; N, 4.19. Found: C, 57.38; H, 4.83; N, 4.00. mp. 183-186 ${ }^{\circ} \mathrm{C}$.

\section{Synthesis of compound 4}

45 A mixture of tetramethoxy resorcinarene ${ }^{12}(0.50 \mathrm{~g}, 0.76 \mathrm{mmol})$, 4-bromobenzyl bromide $(0.78 \mathrm{~g}, 3.10 \mathrm{mmol}), \mathrm{K}_{2} \mathrm{CO}_{3}(0.44 \mathrm{~g}$, $3.17 \mathrm{mmol})$ and 18 -crown-6 (0.03 g, $0.13 \mathrm{mmol})$ was suspended in dry acetonitrile $(40 \mathrm{ml})$ with stirring under nitrogen and warmed to $60{ }^{\circ} \mathrm{C}$ (bath temperature). The light yellow suspension 50 was stirred overnight, upon which it changed to clear yellow solution with a white precipitate. After cooling to room temperature the reaction mixture was filtered by suction and the solvent removed under vacuum. The resulting yellowish solid was recrystallized from ethanol-chloroform solution. Yield: 0.87 $55 \mathrm{~g}(86 \%)$ of white crystalline solid. ${ }^{1} \mathrm{H} \mathrm{NMR}:\left(\mathrm{CDCl}_{3}, 500 \mathrm{MHz}\right)$ $\delta 0.94\left(12 \mathrm{H}, \mathrm{t}, \mathrm{J}=7.25 \mathrm{~Hz}, \mathrm{CH}_{3}\right) 1.86-1.95\left(8 \mathrm{H}, \mathrm{m}, \mathrm{CH}_{2}\right), 3.42$ $(12 \mathrm{H}, \mathrm{s}, \mathrm{OMe}), 4.46(4 \mathrm{H}, \mathrm{t}, \mathrm{J}=7.48 \mathrm{~Hz}, \mathrm{CH}), 4.76(8 \mathrm{H}, \mathrm{AB}$ quartet, $\mathrm{J}=11.75$ and $\left.113.98 \mathrm{~Hz}, \mathrm{CH}_{2}\right), 6.31(4 \mathrm{H}, \mathrm{s}, \mathrm{ArH}), 6.71$ $(4 \mathrm{H}, \mathrm{s}, \mathrm{ArH}), 7.13(8 \mathrm{H}, \mathrm{d}, \mathrm{J}=8.15 \mathrm{~Hz}, \mathrm{BnH}), 7.42(8 \mathrm{H}, \mathrm{d}, \mathrm{J}=$ $\left.{ }_{60} 8.40 \mathrm{~Hz}, \mathrm{BnH}\right) \mathrm{ppm} .{ }^{13} \mathrm{C} \mathrm{NMR}:\left(\mathrm{CDCl}_{3}, 126 \mathrm{MHz}\right) \delta 13.0,27.6$, 37.6, 55.7, 70.4, 97.7, 121.6, 126.3, 126.5, 126.6, 129.1, 131.5, 137.0, 155.1, 155.9 ppm. MS (ESI-TOF): $\mathrm{m} / z, 1355.29[\mathrm{M}+\mathrm{Na}]^{+}$, 1371.26 $[\mathrm{M}+\mathrm{K}]^{+}$. Anal. Calcd. for $\mathrm{C}_{68} \mathrm{H}_{68} \mathrm{O}_{8} \mathrm{Br}_{4}: \mathrm{C}, 61.28 ; \mathrm{H}$, 5.14. Found: C, 61.44 ; H, 5.13. mp. $102-104{ }^{\circ} \mathrm{C}$. 


\section{Crystal structure determination}

The single crystal X-ray diffraction data were recorded on a Nonius Kappa CCD diffractometer with Apex II detector at 173 $\mathrm{K}$, using graphite monochromatized $\mathrm{CuK}_{\alpha}\left[\lambda\left(\mathrm{CuK}_{\alpha}\right)=1.54178\right.$ ${ }_{5} \AA$ A]. The data were processed with Denzo-SMN v0.97.638. ${ }^{18}$ The structures were solved using direct methods (SHELXS-97 ${ }^{19}$ ) and refinements based on $F^{2}$ were made by full matrix least-squares techniques (SHELXL-9 $7^{20}$ ). The hydrogen atoms were calculated to their idealized positions with isotropic temperature factors (1.2 10 or 1.5 times the $\mathrm{C}$ temperature factor) and refined as riding atoms. Absorption correction ${ }^{21}$ was made for all structures but was not used in the final refinement of the structure II (poorer Rvalue). Figures of the structures were drawn with Mercury ${ }^{22}$, ViewerLite $^{23}$ and Ortep ${ }^{24}$. The crystallographic parameters are 15 displayed in Table 2.

In structure I the solvent chloroform was disordered over two positions (0.50:0.50) and its bonding distances were restraint to be equal (SADI). The temperature factors of $\mathrm{C} 10 \mathrm{~B}$ and $\mathrm{ClB}$ were fixed (SIMU) with the anisotropic displacement parameters of ${ }_{20} \mathrm{C} 10 \mathrm{~A}$ and $\mathrm{Cl} 3 \mathrm{~A}$, respectively. In structure II one alkyl chain of the lower rim was disorder over two positions (C34A and C34B 0.50:0.50). $\mathrm{C} 51$ of one $\mathrm{CH}_{2}$ group between an oxygen and pyridine ring was disordered over two positions with site occupancies of 0.68:0.32. The temperature factors of C51A and

${ }_{25} \mathrm{C} 51 \mathrm{~B}$ were restrained (EADP) with the anisotropic displacement parameter of $\mathrm{C} 41$. The carbons of two of the solvent dichloromethanes are disordered over two positions (0.73:0.27 and $0.25: 0.25$ ) and the bonding distances in both cases were restraint to be equal (SADI). The temperature factor of carbon ${ }_{30} \mathrm{C} 10 \mathrm{~B}$ is equalized with the temperature factor of C10A (EADP) and the solvent dichloromethane with the site occupancy of 0.5 is refined isotropically. The temperature factor of one chlorine atom Cl1B was fixed using SIMU with the anisotropic displacement parameter of C11A. Disorder was not constructed for the third 35 solvent dichloromethane (C200) because of lack of electron density. In the structures III and IV, residual electron densities Q $>1$ were found close to bromine and, close to chlorine of the solvent chloroform in structure III, but no chemically meaningful disorder could be constructed.

40 Crystallographic data for the structures in this paper have been deposited with the Cambridge Crystallographic Data Centre as supplementary publication nos. CCDC 886445-886448. The copies of the data can be obtained free of charge via www.ccdc.cam.ac.uk/data_request/cif.

\section{${ }_{45}$ Acknowledgements}

Mr. Esa Haapaniemi is thanked for his help with the NMR studies. Financial support from the National Doctoral Programme in Nanoscience (NGS-Nano) is greatly appreciated.

\section{Notes and references}

${ }_{50}{ }^{a}$ Nanoscience Center, Department of Chemistry, University of Jyväskylä, P.O. Box 35 Jyväskylä FI-40014 Finland. E-mail: maija.nissinen@jyu.fi; Tel: +358142604242

$\dagger$ Electronic Supplementary Information (ESI) available: ${ }^{1} \mathrm{H}$ and ${ }^{13} \mathrm{C}$ NMR spectra of compounds $\mathbf{3}$ and $\mathbf{4}$; specific description of the 55 crystallization experiments; additional ORTEP plots and figures of the crystal structures. See DOI: 10.1039/b000000x/ $\ddagger$ Complexation experiments with $\mathrm{Cu}$ (II) salt in solution were performed by NMR spectroscopic techniques, but no clear indication of the complexation was observed. The crystals obtained were from these 60 experiments.

$\S$ The distance of the methine planes (C7-C14-C21-C28) of the neighboring resorcinarenes.

If Dihedral angles against the methine plane are $87.0^{\circ} / 83.82^{\circ}$ and $174.60^{\circ} / 179.30^{\circ}$.

1 For a review see: a) P. Metrangelo, F. Meyer, T. Pilati, G. Resnati and G. Terraneo, Angew. Chem., Int. Ed., 2008, 47, 6114-6127; b) P. Metrangolo, G. Resnati1 T. Pilati, R. Liantionio, F. Meyer, J. Polym. Sci., Part A: Polym. Chem., 2007, 45, 1-15.

2 A. C. Legon in Halogen Bonding Fundamentals and Applications, ed. P. Metrangolo and G. Resnati, Springer, Berlin, 2008, pp. 17-64.

3 See for example: a) G. R. Desijaru, Nature, 2001, 413, 397-400; b) P. Metrangolo and G. Resnati, Chem. --Eur. J., 2001, 7, 2511-2519; c) E. Bosch and C. L. Barnes, Cryst. Growth Des., 2002, 2, 299-302; d) D. Braga, L. Brammer and N. Champness, CrystEngComm, 2005, 7, 1-19; e) C. B. Aakeröy, P. D. Chopade and J. Desper, Cryst. Growth Des., 2011, 11, 5333-5336.

4 a) J. A. R. P. Sarma, F. H. Allen, V. J. Hoy, J. A. K. Howard, R. Thaimattam, K. Biradha and G. R. Desiraju, Chem. Commun., 1997, 101-102; b) J. Hulliger and P. J. Langley, Chem. Commun., 1998, 2557-2558; c) P. K. Thallapally, G. R. Desiraju, M. Bagieu-Beucher, R. Masse, C. Bourgogne and J. F. Nicoud, Chem. Commun., 2002, 1052-1053; d) E. Cariati, A. Forni, S. Biella, P. Metrangolo, F. Meyer, G. Resnati, S. Righetto, E. Tordin and R. Ugo, Chem. Commun., 2007, 2590-2592.

5 For a review see: a) W. Sliwa and C. Kozlowski in Calixarenes and Resorcinarenes, Wiley-VCH, Weinheim, 2009; b) P. Timmerman, W. Verboom and D. N. Reinhoudt, Tetrahedron, 1996, 52, 26632704.

6 See for example: a) X. Yang, D. McBranch, B. Swason and D. Li, Angew. Chem., Int. Ed., 1996, 35, 538-540; b) D. Li, W. Yang and D. McBranch, Synth. Met., 1997, 86, 1849-1850; c) E. Kelderman, G. J. T. Heesink, L. Derhaeg, T. Verbiest, P. T. A. Klaase, W. Verboom, J. F. J. Engbersen, N. F. van Hulst, A. Persoons and D. N. Reinhoudt, Angew. Chem. Int. Ed. Engl., 1992, 31, 1075-1077; d) E. Kelderman, L. Derhaeg, G. J. T. Heesink, W. Verboom, J. F. J. Engbersen, N. F. van Hulst, K. Clays, A. Persoons and D. N. Reinhoudt, Adv. Mater., 1993, 5, 925-930; e) P. J. A. Kenis, O. F. J. Noordman, H. Schönherr, E. G. Kerver, B. H. M. Snellink-Ruël, G. J. van Hummel, S. Harkema, C. P. J. M. van der Vorst, J. Hare, S. J. Picken, J. F. J. Engbersen, N. F. van Hulst, G. J. Vancso and D. N. Reinhoudt, Chem. --Eur. J., 1998, 4, 1225-1234; f) F. Vocanson, P. Seigle-Ferrand, R. Lamartine, A. Fort , A. W. Coleman, P. Shahgaldian, J. Mugnier and A. Zerroukhi, J. Mater. Chem., 2003, 13, 1596-1602.

7 a) Andreas Vargas Jentzsch, D. Emery, J. Mareda, P. Metrangolo, G. Resnati and S. Matile, Angew. Chem. Int. Ed., 2011, 50, 1167511678; b) M. T. Messina, P. Metrangolo, S. Pappalardo, M. F. Parisi, T. Pilati and G. Resnati, Chem. --Eur.J., 2000, 6, 3495-3500; c) A. Casnati, G. Cavallo, P. Metrangolo, G. Resnati, F. Ugozzoli and R. Ungaro, Chem. --Eur. J., 2009, 15, 7903-7912.

8 a) C. L. D. Gibb, E. D. Stevens and B. C. Gibb, J. Am. Chem. Soc., 2001, 123, 5849-5850; b) Z. R. Laughrey, C. L. D. Gibb, T. Senechal and B. C. Gibb, Chem. --Eur. J., 2003, 9, 130-139; c) Z. R. Laughrey, T. G. Upton and B. C. Gibb, Chem. Commun., 2006, 970972; d) G. Wagner, W. Knoll, M. M. Bobek, L. Brecker, H. W. G. van Herwijnen and U. H. Brinker, Org. Lett., 2010, 12, 332-335.

9 S. J. Dalgarno, N. P. Power, J. Antesberger, R. M. McKinlay and J. L. Atwood, Chem. Commun., 2006, 3803-3805.

10 B. K. Saha, A. Nangia and J.-F. Nicoud, Cryst. Growth Des., 2006, 6, 1278-1281.

11 a) R. G. Hicks, B. D. Koivisto and M. T. Lemaire, Org. Lett., 2004, 6, 1887-1890; b) X. Li, C. L. D. Gibb, M. E. Kuebel and B. C. Gibb, Tetrahedron, 2001, 57, 1175-1182; c) A. Puglisi, M. Benaglia and G. Roncan, Eur. J. Org., Chem. 2003, 1552-1558. 
12 M. J. McIldowie, M. Mocerino, B. W. Skelton and A. H. White, Org. Lett., 2000, 2, 3869-3871.

13 K. Salorinne and M. Nissinen, CrystEngComm, 2009, 11, 15721578.

14 G. R. Desiraju and R. Parthasarathy, J. Am. Chem. Soc., 1989, 111, 8725-8726.

15 V. R. Pedireddi, D. Shekhar Reddy, B. Satish Goud, D. C. Craig, A. D. Rae and G.R. Desiraju, J. Chem. Soc., Perkin Trans. 2, 1994, 2353-2360.

16 M. J. Mclldowie, M. Mocerino, M. I. Ogden and B. W. Skelton, Tetrahedron, 2007, 63, 10817-10825. See structure: CCDC 666176.

17 M. Luostarinen, K. Salorinne, H. Lähteenmäki, H. Mansikkamäki, C. A. Schalley, M. Nissinen and K. Rissanen, J. Incl. Phenom.

Macrocyclic Chem., 2007, 58, 71-80. See structure: CCDC 280272.

18 Z. Otwinowski and W. Minor in Processing of X-ray Diffraction Data Collected in Oscillation Mode, Methods in Enzymology, Molecular Crystallography, Part A, ed. C. W. Carter and R. M. Sweet, Academic Press, New York, 1997, vol. 276, pp. 307-326.

19 a) G. M. Sheldrick, Acta Crystallogr. Sect. A, 2008, 64, 112-122; b) G. M. Sheldrick, Acta Crystallogr. Sect. A, 1990, 46, 467-473.

20 G. M. Sheldrick, Programs for Crystal Structure Solution and Refinement, University of Göttingen, Göttingen, Germany, 1997.

21 R. H. Blessing, Acta Crystallogr. Sect. A, 1995, 51, 33-38.

22 Mercury, version 3.0, CCDC, Cambridge, UK, 2011. See also: C. F. Macrae, P. R. Edgington, P. McCabe, E. Pidcock, G. P. Shields, R. Taylor, M. Towler and J. van de Streek, J. Appl. Crystallogr., 2006, 39, 453-457.

23 ViewerLite, version 5.0, Accelrys Software Inc., San Diego, USA, 2002.

24 ORTEP-3 for Windows, version 2.02, See also: J. L. Farrugia, J. Appl. Crystallogr., 1997, 30, 565. 